\title{
Correlations of Essential Amino Acid Patterns between the Dietary Protein and the Blood, Hepatopancreas, or Skeletal Muscle in Carp
}

\author{
Hiroshi Ogata* \\ (Accepted July 11, 1985)
}

\begin{abstract}
To study the relevance of the dietary essential amino acid (EAA) pattern and the free EAA pattern in fish body, free amino acid (FAA) compositions in the whole blood, plasma, erythrocytes, hepatopancreas, and skeletal muscle of carp Cyprinus carpio were determined at 1, 2, 4, 6, 8, 12, 24, and $72 \mathrm{~h}$ after feeding with a casein-gelatin diet. Correlation coefficient between the dietary EAA pattern and that of free EAA in the whole blood, plasma, or erythrocytes became rapidly higher after food intake, reached to the highest levels within $4 \mathrm{~h}$, and fell gradually to nonsignificant levels by $24 \mathrm{~h}$. The highest correlation coefficients between the whole blood, plasma and erythrocytes, and the diet were $0.8961,0.8273$ and 0.7382 , respectively. Similar trend was also found in the hepatopancreas whose highest correlation coefficients observed at $4 \mathrm{~h}$ was 0.9142, while the skeletal muscle did not show any significant correlations to the diets during the experiment. Thus, EAA pattern of the diet was best reflected in free EAA pattern of the whole blood, plasma, and hepatopancreas at $4 \mathrm{~h}$ after food intake.
\end{abstract}

Recently, Murai et al. ${ }^{1)}$ claimed that essential amino acid (EAA) index based on essential amino acid $(\mathrm{A} / \mathrm{E})$ ratio of a diet is an excellent indicator to evaluate dietary protein quality for carp Cyprinus carpio. However, in certain cases the dietary EAA data alone may be insufficient for evaluation of the protein quality, because of the difference in availability of the ingredients used. From this stand point, not only chemical analysis but also biological and biochemical assessments may be needed. So far, effects of dietary amino acids on free amino acid (FAA) profile in the various tissues have been intensively studied in many fishes, ${ }^{2-24)}$ and assessments of dietary protein quality have been attempted based on these results. $^{2-5}$ Sequential changes in FAA pattern reflecting the dietary composition after food intake have been also revealed in the body of various fishes. ${ }^{8,8-8,14,16,18-20,24)}$ Thus, FAA pattern in the body also may be strongly affected by the time after feeding. Therefore, post-feeding change in the FAA pattern should be sufficiently studied to apply the FAA profile for assessments of the protein quality of a particular diet. The postfeeding changes of FAA levels in the whole blood, plasma, erythrocytes, hepatopancreas, and skeletal muscle were examined in order to study relationship between the dietary EAA pattern and those of free EAA in these tissues.

\section{Methods}

Composition of the experimental diet used was exactly the same as that employed in the previous experiment $^{24)}$ and has been reported in detail by Murai et al. ${ }^{1}$ Amino acid composition of the diet is shown in Table 1. Also, carp with mean weight of about $60 \mathrm{~g}$ were reared under the previously reported manner. ${ }^{24}$ Fish having been starved for $48 \mathrm{~h}$ were taken for zero time samples, and the remaining fish were immediately fed the diet at a level of $3 \%$ of body weight. At $1,2,4$, $6,8,12,24$, and $72 \mathrm{~h}$ after feeding, blood samples were collected from the caudal peduncle after anesthetizing with $0.01 \%$ solution of MS-222. Then, the fish were sacrificed for sampling of the hepatopancreas and dorsal skeletal muscle without dark muscle. All samplings were made in duplication. Sample preparation and FAA determination of the whole blood, plasma, and erythrocytes were performed as has been reported before. ${ }^{24,20)}$ FAA extraction from the hepatopancreas and skeletal muscle was carried out according to a slightly modified method of Eckhert and Kemmerer. ${ }^{26)}$ Each tissue was thoroughly minced and lyophilized. To a portion of the dried tissue, weighing 40 to $50 \mathrm{mg}, 4 \mathrm{~m} l$ of $15 \%$ solution of sulfosalycilic acid was added. The mixture was mechanically shaken for $30 \mathrm{~min}$ at room tem-

* Inland Station, National Research Institute of Aquaculture; Tamaki, Mie 519-04, Japan (尾形 博：震 林水産省羡殖研究所). 
perature, stood at $4^{\circ} \mathrm{C}$ overnight, and shaken again. The suspension was centrifuged at 9,000 rpm for $15 \mathrm{~min}$, and the supernatant obtained was analyzed for FAA. FAA were determined using an automatic amino acid analyzer (Hitachi Model 835).

\section{Results}

\section{Blood}

Postprandial levels of FAA in the whole blood, plasma and erythrocytes of carp are listed in Table 1,2 and 3, respectively. In the previous report, ${ }^{, 4)}$ FAA contents in the plasma and erythrocytes were expressed as levels per one liter of the whole blood to examine distribution of FAA in the blood, while the present values were shown as levels per one liter of plasma and erythrocytes, respectively. Irrespective to the representation used, the nature of postprandial changes in FAA levels of the blood samples agreed well with the previous results ${ }^{24)}$ which were already discussed in detail. Correlation coefficients ( $x$ ) between the dietary EAA and free EAA in the whole blood increased from 0.5701 of the zero time to the highest value of 0.8961 at $4 \mathrm{~h}$ after food intake (Table 6). Then, it decreased to non significant level at $8 \mathrm{~h}$, became significant again at $12 \mathrm{~h}$, and returned to the initial level by $24 \mathrm{~h}$. Similar trends were also observed in the plasma and erythrocytes. However, these values were slightly lower than those in the whole blood. The highest correlation coefficients of the plasma and erythrocytes were 0.8273 and 0.7382 at $4 \mathrm{~h}$ after food intake, respectively (Table 6).

\section{Hepatopancreas}

Postprandial change of FAA contents in the

Table 1. Postprandial levels of free amino acids in the whole blood of carp ( $\mu \mathrm{mol} / l$ of whole blood)

\begin{tabular}{|c|c|c|c|c|c|c|c|c|c|c|}
\hline \multirow{2}{*}{ Amino acids } & \multicolumn{9}{|c|}{ Hours after feeding } & \multirow{2}{*}{$\operatorname{Diet}^{* 1}$} \\
\hline & Start & 1 & 2 & 4 & 6 & 8 & 12 & 24 & 72 & \\
\hline Taurine & 7682 & 7235 & 7191 & 7427 & 7021 & 7459 & 7274 & 7082 & 7280 & \\
\hline Aspartic acid & 75 & 86 & 79 & 44 & 42 & 60 & 34 & 49 & 63 & 163 \\
\hline Threonine & 223 & 368 & 544 & 615 & 718 & 673 & 414 & 415 & 740 & 96 \\
\hline Serine & 190 & 238 & 366 & 626 & 801 & 921 & 527 & 403 & 358 & 160 \\
\hline Glutamic acid & 119 & 137 & 163 & 154 & 179 & 229 & 158 & 197 & 232 & 400 \\
\hline Glutamine & 600 & 562 & 778 & 1200 & 879 & 796 & 743 & 598 & 704 & \\
\hline Glycine & 710 & 547 & 451 & 693 & 1076 & 1561 & 1002 & 908 & 849 & 365 \\
\hline Alanine & 611 & 518 & 718 & 1094 & 1472 & 1250 & 697 & 770 & 1065 & 173 \\
\hline Valine & 229 & 313 & 455 & 608 & 531 & 427 & 463 & 277 & 392 & 139 \\
\hline Cystine & 6 & n.d. & n.d. & n.d. & n.d. & n.d. & n.d. & 8 & 3 & \\
\hline Methionine & 46 & 104 & 175 & 210 & 131 & 72 & 80 & 69 & 60 & $63^{* 2}$ \\
\hline Isoleucine & 108 & 146 & 238 & 361 & 321 & 218 & 224 & 113 & 230 & 97 \\
\hline Leucine & 225 & 525 & 738 & 732 & 445 & 308 & 339 & 213 & 447 & 182 \\
\hline Tyrosine & 52 & 274 & 443 & 333 & 311 & 243 & 141 & 157 & 92 & \\
\hline Phenylalanine & 51 & 296 & 492 & 448 & 297 & 208 & 144 & 138 & 132 & $159 * 3$ \\
\hline Ammonia & 369 & 474 & 843 & 1603 & 1182 & 1044 & 1071 & 1138 & 1186 & \\
\hline Tryptophan & 20 & 64 & 65 & 39 & 20 & 19 & 25 & 33 & 21 & 13 \\
\hline Lysine & 296 & 504 & 755 & 816 & 637 & 557 & 496 & 533 & 928 & 134 \\
\hline Histidine & 191 & 284 & 398 & 341 & 234 & 263 & 220 & 259 & 348 & 48 \\
\hline Arginine & 84 & 324 & 382 & 317 & 238 & 226 & 202 & 200 & 342 & 93 \\
\hline Hydroxyproline & 346 & 415 & 255 & 319 & 459 & 956 & 936 & 672 & 484 & 80 \\
\hline Proline & 3163 & 2868 & 1676 & 2664 & 3996 & 6538 & 4842 & 5032 & 4779 & 336 \\
\hline$\Sigma E A A$ & 1531 & 3201 & 4686 & 4818 & 3881 & 3214 & 2748 & 2415 & 3638 & \\
\hline ENAA & 5812 & 5371 & 4486 & 6795 & 8905 & 12311 & 8937 & 8628 & 8553 & \\
\hline$\Sigma$ NRS & 15394 & 16281 & 17206 & 20643 & 20988 & 24028 & 20030 & 19263 & 20753 & \\
\hline
\end{tabular}

All values represent the mean of two smaples.

*1 Amino acid contents of the experimental diet having the mixture of casein-gelatin $(5: 2$, w/w) as a protein source are expressed as mol/100 $\mathrm{g}$ of dry diet.

*2 Total amount of methionine and cystine.

*8 Total amount of phenylalanine and tyrosine.

EAA: essential amino acid. NAA: nonessential amino acid. NRS: ninbydrin reacting substance. n.d.: not detected. 
Table 2. Postprandial levels of free amino acids in the plasma of carp ( $\mu \mathrm{mol} / l$ of plasma)

\begin{tabular}{|c|c|c|c|c|c|c|c|c|c|c|}
\hline & \multirow{2}{*}{ Amino acids } & \multicolumn{9}{|c|}{ Hours after feeding } \\
\hline & & Start & 1 & 2 & 4 & 6 & 8 & 12 & 24 & 72 \\
\hline & Taurine & 505 & 502 & 601 & 613 & 638 & 766 & 574 & 496 & 796 \\
\hline & Aspartic acid & 29 & 8 & 10 & 249 & 9 & 8 & 84 & 51 & 13 \\
\hline & Threonine & 149 & 293 & 511 & 662 & 797 & 732 & 412 & 287 & 657 \\
\hline & Serine & 105 & 201 & 366 & 651 & 868 & 978 & 505 & 254 & 288 \\
\hline & Glutamic acid & n.d. & 17 & 86 & n.d. & 82 & 109 & 24 & 45 & 73 \\
\hline & Glutamine & 383 & 493 & 807 & 1321 & 928 & 850 & 764 & 411 & 606 \\
\hline & Glycine & 422 & 370 & 292 & 586 & 1171 & 1727 & 1117 & 636 & 720 \\
\hline & Alanine & 406 & 407 & 664 & 1142 & 1630 & 1261 & 580 & 515 & 868 \\
\hline & Valine & 240 & 356 & 522 & 724 & 613 & 495 & 506 & 230 & 431 \\
\hline & Cystine & n.d. & n.d. & 5 & 4 & 6 & 10 & 6 & 6 & 11 \\
\hline & Methionine & 45 & 152 & 258 & 241 & 159 & 97 & 86 & 65 & 81 \\
\hline & Isoleucine & 111 & 178 & 290 & 431 & 363 & 244 & 252 & 100 & 258 \\
\hline & Leucine & 238 & 665 & 891 & 822 & 472 & 334 & 375 & 191 & 496 \\
\hline & Tyrosine & 43 & 259 & 420 & 303 & 298 & 238 & 137 & 134 & 103 \\
\hline & Phenylalanine & 60 & 291 & 472 & 416 & 285 & 203 & 136 & 117 & 130 \\
\hline & Ammonia & 322 & 406 & 777 & 938 & 547 & 413 & 273 & 310 & 445 \\
\hline & Tryptophan & 12 & 63 & 54 & 32 & 16 & 20 & 20 & 23 & 23 \\
\hline & Lysine & 404 & 737 & 1127 & 1163 & 870 & 761 & 608 & 538 & 1230 \\
\hline & Histidine & 211 & 338 & 484 & 384 & 232 & 295 & 234 & 264 & 388 \\
\hline & Arginine & 107 & 528 & 591 & 439 & 309 & 316 & 238 & 184 & 434 \\
\hline & Hydroxyproline & 320 & 365 & 217 & 300 & 526 & 1277 & 1253 & 723 & 505 \\
\hline & Proline & 3318 & 2413 & 1143 & 2466 & 4335 & 7873 & 5815 & 5098 & 4951 \\
\hline & $\Sigma \mathrm{EAA}$ & 1619 & 3861 & 5623 & 5618 & 4419 & 3745 & 3009 & 2139 & 4241 \\
\hline & SNAA & 4954 & 4283 & 3574 & 6466 & 9541 & 14074 & 10059 & 7683 & 8010 \\
\hline & NNRS & 7400 & 9051 & 10574 & 13635 & 15145 & 18998 & 13915 & 10627 & 13492 \\
\hline
\end{tabular}

Table 3. Postprandial levels of free amino acids in the erythrocytes of carp ( $\mu \mathrm{mol} / l$ of erythrocytes)*

\begin{tabular}{|c|c|c|c|c|c|c|c|c|c|}
\hline \multirow{2}{*}{ Amino acids } & \multicolumn{9}{|c|}{ Hours after feeding } \\
\hline & Start & 1 & 2 & 4 & 6 & 8 & 12 & 24 & 72 \\
\hline Taurine & 19273 & 17549 & 17615 & 18542 & 19298 & 19357 & 19860 & 20192 & 21435 \\
\hline Aspartic acid & 151 & 205 & 190 & n.c. & 106 & 152 & 36 & 76 & 172 \\
\hline Threonine & 342 & 481 & 596 & 541 & 567 & 569 & 419 & 670 & 919 \\
\hline Serine & 327 & 296 & 368 & 588 & 674 & 820 & 568 & 693 & 506 \\
\hline Glutamic acid & 311 & 322 & 285 & 406 & 367 & 442 & 410 & 496 & 569 \\
\hline Glutamine & 948 & 667 & 736 & 1006 & 788 & 701 & 700 & 960 & 909 \\
\hline Glycine & 1175 & 819 & 704 & 871 & 887 & 1266 & 784 & 1433 & 1121 \\
\hline Alanine & 940 & 687 & 804 & 1021 & 1174 & 1231 & 916 & 1264 & 1477 \\
\hline Valine & 211 & 248 & 351 & 421 & 376 & 306 & 382 & 377 & 303 \\
\hline Cystine & 15 & n.c. & n.c. & n.c. & n.c. & n.c. & n.c. & 14 & n.c. \\
\hline Methionine & 48 & 30 & 45 & 159 & 77 & 26 & 68 & 77 & 14 \\
\hline Isoleucine & 103 & 97 & 156 & 248 & 240 & 172 & 174 & 137 & 170 \\
\hline Leucine & 205 & 311 & 499 & 584 & 396 & 264 & 271 & 254 & 341 \\
\hline Tyrosine & 67 & 296 & 481 & 382 & 337 & 253 & 150 & 200 & 70 \\
\hline Phenylalanine & 37 & 303 & 524 & 499 & 321 & 217 & 160 & 178 & 133 \\
\hline Ammonia & 444 & 579 & 947 & 2688 & 2406 & 2167 & 2569 & 2789 & 2791 \\
\hline Tryptophan & 35 & 67 & 84 & 51 & 27 & 17 & 34 & 51 & 18 \\
\hline Lysine & 121 & 146 & 170 & 253 & 190 & 194 & 285 & 529 & 307 \\
\hline Histidine & 159 & 201 & 262 & 270 & 240 & 206 & 193 & 245 & 258 \\
\hline Arginine & 46 & 14 & 53 & 120 & 102 & 67 & 139 & 227 & 152 \\
\hline Hydroxyproline & 385 & 491 & 316 & 350 & 329 & 387 & 339 & 583 & 447 \\
\hline $\begin{array}{l}\text { Proline } \\
\end{array}$ & 2914 & 3538 & 2520 & 2996 & 3349 & 4163 & 3022 & 4921 & 4546 \\
\hline IEAA & 1389 & 2192 & 3220 & 3528 & 2873 & 2289 & 2238 & 2959 & 2684 \\
\hline$\Sigma \mathrm{NAA}$ & 6999 & 6820 & 5732 & 7239 & 7568 & 9009 & 6740 & 10395 & 9574 \\
\hline ZNRS & 28106 & 27139 & 27515 & 31997 & 32144 & 32819 & 31443 & 36334 & 36484 \\
\hline
\end{tabular}

See Table 1 .

* Free amino acid contents in the erythrocytes were calculated form the whole blood and plasma contents with correction by hematocrit values, so called "calculated erythrocytes contents". 
Table 4. Postprandial levels of free amino acids in the hepatopancreas of carp ( $\mathrm{mmol} / \mathrm{kg}$ of dried tissue)

\begin{tabular}{|c|c|c|c|c|c|c|c|c|c|}
\hline \multirow{2}{*}{ Amino acids } & \multicolumn{9}{|c|}{ Hours after feeding } \\
\hline & Start & 1 & 2 & 4 & 6 & 8 & 12 & 24 & 72 \\
\hline Taurine & 41.37 & 39.39 & 39.70 & 35.76 & 39.13 & 35.62 & 32.94 & 33.63 & 44.41 \\
\hline Aspartic acid & 1.18 & 0.43 & 0.72 & 1.94 & 2.49 & 0.85 & 0.88 & 1.48 & 1.97 \\
\hline Threonine & 1.86 & 1.84 & 1.93 & 2.82 & 2.82 & 2.92 & 2.27 & 2.39 & 2.61 \\
\hline Serine & 2.13 & 1.70 & 2.06 & 3.89 & 4.07 & 3.79 & 3.50 & 2.59 & 2.02 \\
\hline Glutamic acid & 12.42 & 4.94 & 4.75 & 12.38 & 18.64 & 15.36 & 13.10 & 13.71 & 12.32 \\
\hline Glutamine & 5.42 & 2.73 & 1.88 & 4.18 & 4.68 & 4.39 & 5.87 & 4.40 & 4.50 \\
\hline Glycine & 7.26 & 4.40 & 3.45 & 4.95 & 7.18 & 6.65 & 5.30 & 5.43 & 5.60 \\
\hline Alanine & 14.24 & 6.88 & 7.52 & 14.98 & 20.23 & 15.42 & 11.86 & 13.75 & 12.97 \\
\hline Valine & 1.51 & 2.22 & 2.45 & 3.37 & 2.30 & 1.87 & 2.32 & 1.34 & 1.70 \\
\hline Cystine & 0.10 & 0.11 & 0.10 & 0.11 & 0.07 & 0.07 & 0.09 & 0.06 & 0.08 \\
\hline Methionine & 0.63 & 0.80 & 0.75 & 1.11 & 0.59 & 0.55 & 0.87 & 0.55 & 0.43 \\
\hline Isoleucine & 0.81 & 1.29 & 1.54 & 2.30 & 1.44 & 1.04 & 1.36 & 0.70 & 1.02 \\
\hline Leucine & 1.75 & 3.68 & 3.80 & 4.28 & 2.28 & 1.95 & 2.89 & 1.57 & 2.11 \\
\hline Tyrosine & 0.91 & 1.97 & 2.26 & 2.00 & 1.56 & 1.30 & 1.33 & 1.03 & 0.80 \\
\hline Phenylalanine & 1.02 & 1.31 & 1.58 & 1.66 & 0.98 & 0.91 & 1.34 & 0.86 & 0.83 \\
\hline Ammonia & 15.58 & 16.64 & 16.67 & 16.98 & 19.04 & 18.06 & 15.28 & 15.62 & 20.56 \\
\hline Tryptophan & 0.11 & 0.30 & 0.21 & 0.22 & 0.12 & 0.13 & 0.17 & 0.12 & 0.14 \\
\hline Lysine & 2.64 & 3.23 & 3.11 & 4.67 & 3.49 & 3.44 & 3.90 & 3.06 & 4.60 \\
\hline Histidine & 1.74 & 2.42 & 3.10 & 2.04 & 1.26 & 1.45 & 1.55 & 1.50 & 1.64 \\
\hline Arginine & 1.27 & 2.47 & 2.22 & 2.79 & 1.65 & 1.79 & 2.29 & 1.40 & 2.06 \\
\hline Hydroxyproline & 1.24 & 1.32 & 0.52 & 0.89 & 1.41 & 2.42 & 4.15 & 1.93 & 1.85 \\
\hline Proline & 19.06 & 19.36 & 8.21 & 9.83 & 16.41 & 22.79 & 24.86 & 20.99 & 22.24 \\
\hline$\Sigma$ EAA & 14.33 & 21.65 & 23.05 & 27.36 & 18.57 & 17.41 & 20.38 & 14.58 & 18.01 \\
\hline$\Sigma \mathrm{NAA}$ & 62.94 & 41.76 & 29.12 & 53.04 & 75.10 & 71.68 & 69.52 & 64.29 & 63.47 \\
\hline$\Sigma$ NRS & 134.22 & 119.45 & 108.54 & 133.13 & 151.85 & 142.77 & 138.12 & 128.12 & 146.45 \\
\hline
\end{tabular}

Table 5. Postprandial levels of free amino acids in the dorsal skeletal muscle of carp (mmol/kg of dried tissue)

\begin{tabular}{|c|c|c|c|c|c|c|c|c|c|}
\hline \multirow{2}{*}{ Amino acids } & \multicolumn{9}{|c|}{ Hours after feeding } \\
\hline & Start & 1 & 2 & 4 & 6 & 8 & 12 & 24 & 72 \\
\hline Taurine & 57.85 & 71.61 & 61.28 & 70.56 & 68.98 & 60.24 & 63.04 & 66.77 & 68.43 \\
\hline Aspartic acid & 0.16 & 0.09 & n.d. & 0.55 & 0.29 & 0.20 & 0.41 & 0.32 & 0.38 \\
\hline Threonine & 3.23 & 3.48 & 4.32 & 3.90 & 4.06 & 3.79 & 3.58 & 3.55 & 4.62 \\
\hline Serine & 3.12 & 1.77 & 3.21 & 4.16 & 5.02 & 5.10 & 5.09 & 4.34 & 3.36 \\
\hline Glutamic acid & 2.44 & 2.62 & 3.22 & 4.13 & 2.88 & 3.12 & 3.71 & 2.78 & 3.03 \\
\hline Glutamine & 6.37 & 4.06 & 3.83 & 5.75 & 3.74 & 2.89 & 5.52 & 3.35 & 3.65 \\
\hline Glycine & 33.51 & 25.04 & 27.79 & 29.22 & 32.21 & 29.80 & 31.82 & 24.74 & 23.14 \\
\hline Alanine & 13.37 & 9.72 & 12.77 & 12.97 & 11.82 & 11.70 & 10.17 & 10.98 & 12.05 \\
\hline Valine & 1.31 & 1.56 & 1.83 & 2.44 & 2.50 & 2.19 & 2.27 & 1.37 & 2.00 \\
\hline Methionine & 0.38 & 0.47 & 0.77 & 1.09 & 0.93 & 0.64 & 0.58 & 0.48 & 0.59 \\
\hline Isoleucine & 0.64 & 0.61 & 0.85 & 1.27 & 1.40 & 1.11 & 1.12 & 0.58 & 1.29 \\
\hline Leucine & 1.13 & 1.55 & 2.50 & 2.82 & $\begin{array}{l}1.90 \\
1.99\end{array}$ & 1.40 & 1.48 & 0.93 & 2.23 \\
\hline Tyrosine & 0.37 & 0.59 & 1.41 & 1.57 & 1.63 & 1.25 & 0.83 & 0.80 & 0.67 \\
\hline Phenylalanine & 0.37 & 0.45 & 1.33 & 1.51 & 1.33 & 0.92 & 0.62 & 0.49 & 0.57 \\
\hline Ammonia & 28.63 & 27.37 & 30.26 & 30.45 & 31.44 & 29.50 & 27.85 & 26.10 & 30.33 \\
\hline Tryptophan & n.d. & 0.16 & 0.24 & 0.22 & n.d. & n.d. & n.d. & n.d. & n.d. \\
\hline Lysine & 27.23 & 23.92 & 23.03 & 23.03 & 23.48 & 26.00 & 27.45 & 22.78 & 27.25 \\
\hline Histidine & 70.98 & 71.69 & 77.09 & 73.75 & 71.02 & 85.38 & 72.92 & 72.12 & 78.44 \\
\hline Arginine & 2.77 & 2.19 & 3.98 & 4.86 & 5.48 & $\begin{array}{r}4.69 \\
4.69\end{array}$ & 3.86 & 3.20 & 4.59 \\
\hline Hdroxyproline & 6.15 & 6.54 & 4.23 & 5.49 & 6.25 & 6.89 & 7.42 & 5.98 & 4.19 \\
\hline Asparagine & 3.06 & n.d. & 0.58 & 3.57 & 1.93 & 2.22 & 2.34 & $\begin{array}{l}3.90 \\
1.97\end{array}$ & 1.80 \\
\hline $\begin{array}{l}\text { Proline } \\
\text { Proll }\end{array}$ & 22.32 & 24.73 & 15.99 & 22.51 & 25.55 & 29.91 & 25.22 & 21.67 & 17.59 \\
\hline SEAA & 108.41 & 106.66 & 117.36 & 116.91 & 116.33 & 128.83 & 110.05 & 110.78 & 125.49 \\
\hline SNAA & 90.50 & 74.57 & 71.62 & 88.35 & 89.69 & 91.83 & 91.71 & 76.13 & 69.19 \\
\hline$\Sigma$ NRS & 285.39 & 280.20 & 280.52 & 306.28 & 306.44 & 310.39 & 292.65 & 279.78 & 293.44 \\
\hline
\end{tabular}


Table 6. Correlation coefficients between the dietary EAA pattern and free EAA pattern in the whole blood, plasma, erythrocytes, hepatopancreas, or dorsal skeletal muscle of carp

\begin{tabular}{cccccc}
\hline \multirow{2}{*}{$\begin{array}{c}\text { Hours after } \\
\text { feeding }\end{array}$} & Whole blood & Plasma & Erythrocytes & Hepatopancreas & Skeletal muscle \\
\cline { 2 - 6 } & 5.701 & 5.455 & 3.715 & 4.573 & -2.710 \\
Start & $8.374^{* 3}$ & $7.749^{* 1}$ & 5.493 & $8.298^{* 2}$ & -2.812 \\
1 & $8.395^{* 3}$ & $8.049^{* 2}$ & 6.025 & $7.853^{* 1}$ & -2.819 \\
2 & $8.961^{* 3}$ & $8.273^{* 2}$ & $7.382^{* 1}$ & $9.142^{* 4}$ & -2.724 \\
4 & $7.362^{* 1}$ & $6.937^{* 1}$ & 6.514 & $7.793^{* 1}$ & -2.634 \\
6 & 5.853 & 5.538 & 5.377 & 6.502 & -2.831 \\
8 & $7.175^{* 1}$ & $6.970^{* 1}$ & $6.803^{* 1}$ & $8.106^{* 2}$ & -2.853 \\
12 & 4.944 & 4.666 & 4.737 & 5.651 & -2.724 \\
24 & 4.495 & 4.424 & 2.917 & 5.278 & -2.604 \\
78 & & &
\end{tabular}

${ }^{* 1} p<0.05 * 2 p<0.01 * 3 p<0.005 * 4 p<0.001$

hepatopancreas was principally similar to those found in the blood as shown in Table 4. Almost all of free EAA in the hepatopancreas rose rapidly and attained their highest levels within $4 \mathrm{~h}$. Whereas, levels of most of free nonessential amino acids (NAA) decreased shortly after food intake, and attained the highest values at 6 or $8 \mathrm{~h}$. In all tissues examined, the highest correlation coefficient $(0.9142)$ was found between the diet and hepatopancreas at $4 \mathrm{~h}$ after food intake. Postfeeding change in correlation coefficients was also almost similar to those in the blood.

Skeletal Muscle

Levels of free lysine and histidine in the skeletal muscle were surprisingly high compared with those of other free EAA detected (Table 5). Free lysine and histidine represented approximately 25 and $65 \%$ of the total free EAA content, respectively. Levels of lysine and histidine did not show any consistent changes after food intake, though postprandial contents of other free EAA became up to 1.3 to 4.4 times higher than initial values of these. This phenomenon is reflected in the postprandial correlations of free EAA in the skeletal muscle to the dietary EAA, i.e. the correlation coefficients between these did not become significant during the experiment (Table 6).

\section{Discussion}

Changes in post-feeding profile of tissue FAA has been extensively studied in fishes. Nose ${ }^{8}$ found that the plasma FAA pattern shows the best correlation coefficient against the dietary amino acid pattern at $12 \mathrm{~h}$ after food intake in his preliminary study on rainbow trout fed a commercial diet. Kaushik and Luquet $^{8)}$ also obtained a similar result in the whole blood of rainbow trout. Whereas, Schlisio and Nicolai ${ }^{12]}$ demonstrated that there is no distinct correlation between the amino acid contents in the diet and plasma at $12 \mathrm{~h}$ after food intake using rainbow trout fed a synthetic diet containing pure amino acids. The reason for this discrepancy might be partly due to the difference in the experimental diet used. While in carp, Plakas et al. ${ }^{14)}$ reported that the plasma free EAA pattern at $4 \mathrm{~h}$ after food intake is highly and positively correlated to the EAA pattern in a casein diet used. Similarly, the plasma pattern estimated from the results of Murai et al. ${ }^{3}$ where a casein-gelatin mixture was used as a protein source seemed to show the best correlation against the dietary pattern at $4 \mathrm{~h}$. However, the most significant correlation between the values of BEAAp (balance of essential amino acids in plasma which is proposed for an assessment of the quality of dietary protein) and the growth responses was obtained at $6 \mathrm{~h}$ by Murai et $a l^{3}$. Unlike carp, Dabrowska ${ }^{5)}$ recently reported that BEAAp index seemed to be not suitable for rainbow trout. Thus, sequential phase of fluctuation in FAA composition and content in a tissue due to food intake might differ among the species of experimental animals used and rearing temperature. Quality and quantity of the experimental diets taken, and time after feeding can also affect the response of fish. Especially, the very last factor can drastically affect tissue FAA profile. Therefore, when a study on FAA dynamics under various nutritional and physiological conditions is conducted, nutritional history of the experimental fish should be thoroughly studied in advance.

In the skeletal muscle of carp, any significant correlation was not found against the dietary EAA pattern. Absence of distinct peak in the skeletal 
muscular free EAA and NAA during the first $24 \mathrm{~h}$ after food intake was also observed in rainbow trout reared in freshwater by Kaushik and Luquet. ${ }^{\text {) }}$ Thus unlike in the other tissues, FAA patterns in the skeletal muscle seem to be relatively stable and be hardly affected by the time elapsed after food intake. However, the dietary levels of certain amino acids are reflected in those of the skeletal muscle. Therefore, the muscular analysis also can be used for biochemical prediction of the EAA requirement of fishes as have been described in higher vertebrates by Pion. ${ }^{27)}$ According this principal, Kaushik ${ }^{13)}$ made the biochemical estimation of arginine needed for rainbow trout in different salinities and obtained the results which are well consistent with those through growth studies using diets containing graded levels of arginine.

Free EAA pattern in the whole blood at $4 \mathrm{~h}$ after food intake showed stronger correlation against the dietary EAA pattern than that of plasma. As have been claimed by Pion, ${ }^{27}$ Kaushik and Luquet, ${ }^{8)}$ and Kaushik, ${ }^{13)}$ whole blood seems to reflect the dietary amino acid composition better than plasma. Recently, the author found in the study using carp fed a casein-gelatin diet that certain EAA, especially aromatic amino acids, can distribute not only in the plasma but also in the erythrocytes after food intake and appeared to be transported partially by the erythrocytes. ${ }^{24)}$ Therefore, plasma analysis would result in underestimation owing to amino acids present in erythrocytes. However, simple aminogram can be obtained by the plasma analysis compared to the whole blood and hepatopancreas analyses. Also, the degree of fluctuation in the plasma FAA by food intake seems to be more distinct and wider than those in the whole blood and hepatopancreas. Thus, judging from these points, plasma analysis appears to be almost as good as whole blood and hepatopancreas analysis in evaluation of the quality of dietary protein.

\section{Acknowledgement}

The author wishes to thank Drs. S. Arai and T. Murai, National Research Institute of Aquaculture, for critically reviewing the manuscript.

\section{References}

1) T. Murai, T. Akiyama, and T. Nose: Bull. Japan. Soc. Sci. Fish, 50, 893-897 (1984).

2) M. F. Zébian and Y. Créach: in "Finfish Nutrition and Fishfee Tdechnology" (ed. by J. E. Halver and $\mathrm{K}$. Tiews), Vol. I, Heenemann Verlagsgesellshaft mbH, Berlin, 1979, pp. 531-544.

3) T. Murai, T. Akiyama, H. Ogata, Y. Hirasawa, and T. Nose: Bull. Japan. Soc. Sci. Fish., 48, 703-710 (1982),

4) P. H. Fair and L. V. Sick: Comp. Biochem. Physiol, 73B, 195-200 (1982).

5) H. Dabrowska: Comp. Biochem. Physiol., 77A, 553-555 (1984).

6) T. Nose; Bull. Freshwater Fish. Res. Lab., 22, 137-144 (1972)

7) O. Deshimaru: Bull. Japan. Soc. Sci. Fish., 42 , 655-660 (1976).

8) S. Kaushik and P. Luquet: Ann. Hydrobiol., 8, 135-144 (1977).

9) S. Kaushik and P. Luquet: Ann. Hydrobiol., 8, 375-387 (1977).

10) T. Nose, D.-L. Lee, and S. Arai: Bull. Freshwater Fish. Res. Lab., 28, 255-263 (1978).

11) R. P. Wilson, O. W. Allen, Jr., E. H. Robinson, and W. E. Poe: J. Nutr., 108, 1595-1599 (1978).

12) W. Schlisio and B. Nicolai: Comp. Biochem. Physiol., 59B, 373-379 (1978).

13) S. Kaushik: in "Finfish Nutrition and Fish Feed Technology" (ed. by J. E. Halver and $\mathrm{K}$. Tiews), Vol. I, Heenemann Verlagsgesellshaft mbH, Berlin, 1979, pp. 531-544.

14) S. M. Plakas, T. Katayama, $Y$. Tanaka, and $O$. Deshimaru: Aquaculture, 21, 307-322 (1980).

15) R. P. Wilson, W. E. Poe, and E. H. Robinson: J. Nutr., 110, 627-633 (1980).

16) S. Y. Yamada, K. L. Simpson, Y. Tanaka, and T. Katayama: Bull. Japan, Soc. Sci. Fish., 47, 1035-1040 (1981).

17) E. H. Robinson, R. P. Wilson, and W. E. Poe; J. Nutr., 111, 46-52 (1981).

18) K. Dabrowski: Comp. Biochem. Physiol, 72A, 753-763 (1982).

19) K. Dabrowski: Comp. Biochem. Physiol, 72B, 659-662 (1982).

20) S. Yamada, Y. Tanaka, T. Katayama, M. Sameshima, and K. L. Simpson: Bull. Japan. Soc. Sci. Fish., 48, 1783-1787 (1982).

21) H. Barash: Nutr. Rep. Inter., 29, 283-289 (1984).

22) T. Murai, H. Ogata, T. Takeuchi, T. Watanabe, and T. Nose: Bull. Japan. Soc. Sci. Fish., 50, 1957 (1984).

23) H. Ogata, S. Arai, and B. M. Alvare: Bull. Japan. Soc. Sci. Fish., 51, 573-578 (1985).

24) H. Ogata: Bull. Japan. Soc. Sci. Fish., 51, 17051711 (1985).

25) H. Ogata and S. Arai: Bull. Japan. Soc. Sci. Fish., 51, 1181-1186 (1985).

26) C. D. Eckhert and A. R. Kemmerer: J. Nutr., 104, 865-870 (1970).

27) R. Pion: in "Protein Metabolism and Nutrition" (ed. by D. J. A. Cole, K. N. Boorman, P.J. Buttery, D. Lewis, R. J. N. Eale, and H. Swan), Butterworth, London, 1976, pp. 259-277. 